Turner K (2009) Negative rebound and disinvestment effects in response to an improvement in energy efficiency in the UK economy, Energy Economics, 31 (5), pp. 648-666.

This is the peer reviewed version of this article

NOTICE: this is the author's version of a work that was accepted for publication in Energy Economics. Changes resulting from the publishing process, such as peer review, editing, corrections, structural formatting, and other quality control mechanisms may not be reflected in this document. Changes may have been made to this work since it was submitted for publication. A definitive version was subsequently published in Energy Economics, [VOL 31, ISSUE 5, (2009)] DOI: http://dx.doi.org/10.1016/j.eneco.2009.01.008 


\title{
Negative rebound and disinvestment effects in response to an improvement in energy efficiency in the UK economy
}

\author{
By Karen Turner* \\ * Department of Economics, University of Strathclyde, Sir William Duncan Building, \\ 130 Rottenrow, Glasgow G4 OGE. \\ Tel: 44(0)141548 3864. $\quad$ E-mail: karen.turner@strath.ac.uk
}

\begin{abstract}
This paper uses a computable general equilibrium (CGE) framework to investigate the conditions under which rebound effects may occur in response to increases in energy efficiency in the UK national economy. Previous work for the UK has suggested that rebound effects will occur even where key elasticities of substitution in production are set close to zero. The research reported in this paper involves carrying out a systematic sensitivity analysis, where relative price sensitivity is gradually introduced into the system, focusing specifically on elasticities of substitution in production and trade parameters, in order to determine conditions under which rebound effects become a likely outcome. The main result is that, while there is positive pressure for rebound effects even where (direct and indirect) demands for energy are very price inelastic, this may be partially or wholly offset by negative income, competitiveness and disinvestment effects, which also occur in response to falling energy prices. The occurrence of disinvestment effects is of particular interest. These occur where falling energy prices reduce profitability in domestic energy supply sectors, leading to a contraction in capital stock in these sectors, which may in turn lead to rebound effects that are smaller in the long run than in the short run, a result that runs contrary to the predictions of previous theoretical work in this area.
\end{abstract}

Keywords: general equilibrium, energy efficiency, rebound effects, disinvestment. JEL D57, D58, R15, Q41, Q43 


\section{Introduction and background}

There has recently been increasing interest in both the academic and policy arenas regarding what have come to be known as "rebound" and "backfire" effects (Jevons, 1865; Khazzoom 1980; Brookes 1990; Herring, 1999; Birol and Keppler, 2000; Saunders, 1992, 2000a,b; Schipper, 2000). A small number of applied general equilibrium analyses of economy-wide rebound effects have been published in the energy economics literature (see, for example, Semboja, 1994, for Kenya; Dufournaud et al, 1994, for the Sudan; Grepperud and Rasmussen, 2004, for Norway; Glomsrød and Taojuan, 2005, for China; Hanley et al, 2006 and 2009 for Scotland; and Allan et al, 2007 for the UK). In a UK policy context, a report from the House of Lords (2005) cited rebound effects as a possible explanation as to why improvements in energy efficiency in the UK have not led to corresponding reductions in energy use at the macro level. Subsequently, the UK Department for Environment, Food and Rural Affairs, DEFRA, commissioned a comparative modelling project on the impacts of increased energy efficiency on the national economy (Herring, 2006; Allan et al, 2006). ${ }^{1}$

The popularity of applied or computable general equilibrium (CGE) models in this context reflects their multi-sectoral nature combined with their fully specified supplyside, facilitating the analysis of both economic and environmental policies. CGE models are particularly suited to studying the drivers of rebound and backfire effects since they allow the system-wide effects of the energy efficiency improvement to be captured. These comprise (i) a need to use less physical energy inputs to produce any given level of output (the pure engineering or efficiency effect); (ii) an incentive to use more energy inputs since their effective price has fallen (the substitution effect); (iii) a compositional effect in output choice, since relatively energy-intensive products benefit more from this fall in the effective price; (iv) an output effect, since supply prices fall and competitiveness increases; and (v) an income effect as real household incomes rise.

Previous work for the UK (Allan et al, 2007) and also for Scotland (Hanley et al, 2006, 2009) has suggested that key parameters in determining the size of rebound effects are elasticities of substitution in production of energy for other inputs (in line with early

\footnotetext{
${ }^{1}$ All of the applications cited above are reviewed in Sorrell (2007) and Allan et al (2008a).
} 
results reported by Saunders, 1992) and price elasticities of direct and derived demands for energy through trade (particularly in small open economies where energy itself is traded). It has also suggested that rebound effects will occur even where key elasticities of substitution in production are set close to zero. This paper investigates these issues further by carrying out more systematic sensitivity analysis for the UK. This involves gradually introducing relative price sensitivity into the system, focusing in particular on elasticities of substitution in production and trade parameters, in order to investigate conditions under which rebound effects are likely to occur.

The key result of the work presented in this paper (developed in more detail in Turner, 2008) is that, while there is positive pressure for rebound effects even where (direct and indirect) demands for energy are very price inelastic, this may be partially or wholly offset by negative income and disinvestment effects, which also occur in response to falling energy prices. The occurrence of disinvestment effects is of particular interest, as these may lead to rebound effects that are smaller in the long run than in the short run, a result that runs contrary to the predictions of theoretical work reported in Wei (2007) and Saunders (2008).

The paper is structured as follows. Section 2 provides a brief account of what is meant by rebound effects in response to an improvement in energy efficiency. Section 3 gives a general introduction to our energy-economy-environment CGE model of the UK, referred, UKENVI. Section 4 outlines the broad properties of the response to a positive energy efficiency shock in both cases. In Section 5 these results are subjected to a systematic sensitivity analysis, by varying the value of production and trade parameters. A summary and conclusions are provided in Section 6.

\section{The rebound effect}

\subsection{A simple theoretical exposition}

Following Hanley et al (2009) and Turner (2008), we begin by distinguishing between energy measured in natural or physical units, E, and efficiency units, $\varepsilon$ (i.e. the effective 
energy service delivered). If we have energy augmenting technical progress at a rate $\rho$, the relationship between the proportionate change in $\mathrm{E}$ and $\varepsilon$ is given as:

$$
\dot{\varepsilon}=\rho+\dot{\mathrm{E}}
$$

This implies that an $\mathrm{X} \%$ increase in energy efficiency has an impact on output (associated with a given amount of physical energy use) that is identical to an $\mathrm{X} \%$ increase in energy inputs, without the efficiency gain.

The increase in energy efficiency has a corresponding impact on the price of energy, when that energy is measured in efficiency units. Specifically:

$$
\dot{\mathrm{p}}_{\varepsilon}=\dot{\mathrm{p}}_{\mathrm{E}}-\rho
$$

where $\mathrm{p}$ represents price and the subscript identifies energy in either physical or efficiency units. If we assume (for now) constant energy prices in physical units, an X\% improvement in energy efficiency generates an X\% reduction in the price of energy in terms of efficiency units, or an $\mathrm{X} \%$ reduction in the implicit or effective price of energy.

With physical energy prices constant, a decrease in the price of energy in efficiency units will generate an increase in the demand for energy in efficiency units. This is the source of the rebound effect. In a general equilibrium context:

$$
\dot{\varepsilon}=-\eta \dot{p}_{\varepsilon}
$$

where $\eta$ is the general equilibrium price elasticity of demand for energy and has been given a positive sign. For an energy efficiency gain that applies across all uses of energy within the economy, the change in energy demand in natural units can be found by substituting equations (2) and (3) into equation (1), giving:

$$
\dot{\mathrm{E}}=(\eta-1) \rho
$$


For an efficiency increase of $\rho$, rebound, R, expressed in percentage terms, is defined as:

$$
R=\left[1+\frac{\dot{E}}{\rho}\right] \times 100
$$

It is important to define the boundaries of the efficiency improvement in measuring the rebound effect. For example, in the empirical work reported here for the UK, energy efficiency is only improved in a subset of its uses: that is, in its use in production, and there, only locally supplied energy (not imports) is affected. The proportionate change in energy use is therefore $\frac{\Delta E_{T}}{E_{I(L)}}$, where the $\mathrm{T}$ and I subscripts stand for total (UK) and industrial respectively and L indicates locally supplied inputs. Similarly, the implied reduction in the price of energy in efficiency units only applies to its use in production, not in elements of final demand, such as household consumption. In these circumstances, the rebound effect should be calculated as:

$$
R=\left[1+\frac{\dot{E}_{T}}{\alpha \rho}\right] \times 100
$$

where $\alpha$ is the share of energy use affected by the efficiency improvement. Here, use of locally supplied energy by industry, $\frac{E_{I(L)}}{E_{T}}$.

The rebound effect in (5) measures the extent to which energy demand fails to fall in line with the increase in energy efficiency. Where rebound is equal to $0 \%$, energy use falls in proportion to the increase in energy efficiency. Rebound values less than $100 \%$ but greater than $0 \%$ imply that there has been some energy saving as a result of the efficiency improvement, but not by the full extent of the efficiency gain. For example, if a $5 \%$ increase in energy efficiency generates a $4 \%$ reduction in energy use, this corresponds to a $20 \%$ rebound. Where rebound is equal to $100 \%$, there is no change in energy use as the result of the change in energy efficiency. Rebound values greater than $100 \%$ imply positive changes in energy use, measured in physical units. This is an extreme case of rebound, commonly referred to as 'backfire'. 
Substituting equation (4) into equation (5), the link between rebound and the general equilibrium price elasticity of demand for energy is made absolutely clear:

$$
R=\eta \times 100
$$

In line with the range of rebound values above, there are four important ranges/points of general equilibrium price elasticity values. If the elasticity is zero, the fall in energy use equals the improvement in efficiency and rebound equals zero. If the elasticity lies between zero and unity, so that energy demand in relatively price inelastic, there is a fall in energy use but some rebound effect. If the elasticity is equal to one (unitary elasticity), the reduction in energy use required given the increase in efficiency is entirely offset by increased demand for energy as a result of the drop in effective price. Where the elasticity is greater than unity, so that demand is relatively price elastic, the net impact is an increase in energy use. With a price elastic general equilibrium demand for energy, rebound is greater than $100 \%$ and backfire occurs.

\subsection{Empirical considerations}

For simplicity, the theoretical exposition above assumes that physical energy prices are held constant. This conceptual approach would be appropriate for a fuel that is imported and where the natural price is exogenous or only changes in line with the demand measured in natural units. However, there are two problems that will introduce greater complexity in the analysis of real economies. The first is that energy is often produced domestically with energy as one of its inputs, with the implication that the price of energy in physical units will be endogenous, giving further impetus for rebound effects. The second is the problem of identifying of the general equilibrium elasticity of demand for energy, $\eta$, which is shown above to be the crucial determinant of the size of rebound effects in response to a given change in energy augmenting technological progress. The responsiveness of energy demand at the aggregate level to changes in (effective and actual) energy prices will depend on a number of key parameters and other characteristics in the economy, as the theoretical analysis of Allan et al (2008b) demonstrates. As well as elasticities of substitution in production, which tend to receive 
most attention in the literature (see Broadstock et al, 2007, for a review) these include: price elasticities of demand for individual commodities; the degree of openness and extent of trade (particularly where energy itself is traded); the elasticity of supply of other inputs/factors; the energy intensity of different activities; and income elasticities of energy demand (the responsiveness of energy demand to changes in household incomes). Thus, the extent of rebound effects is, in practice, always an empirical issue.

Moreover, the analysis of potential rebound effects requires a general equilibrium framework due to the type and range of underlying effects that drive rebound. These can be characterised as follows:

(i) The pure engineering or efficiency effect - demand for energy is reduced as less physical energy inputs are required to produce any given level of output;

(ii) The substitution effect as demand for energy increases as the price of energy falls relative to other input prices;

(iii) The composition effect in output choice at the aggregate level as relatively energy-intensive products benefit more from the fall in effective and/or actual energy prices price;

(iv) The output/competitiveness effect resulting from the fall in supply price of commodities that (directly and/or indirectly) use energy as an input to production;

(v) The income effect resulting from increased real household incomes, which will impact on household consumption of all commodities, including the direct and/or indirect consumption of energy.

\subsection{The disinvestment effect}

The effects listed above are generally accepted in the rebound literature. However, this paper argues a general equilibrium analyses of the economy-wide response to increased energy efficiency and falling actual energy prices (where there is domestic supply of energy) also allows us to consider another potential effect, but this time one that will act to counter effects (ii) to (v) above and dampen long-run rebound effects. This is: 
(vi) The disinvestment effect, which may occur in domestic energy supply sectors if direct and derived demands for energy are not sufficiently elastic to prevent falling energy prices leading to a decline in revenue, profitability and the return on capital in these sectors. This constrains the elasticity of supply of energy, putting upward pressure on the actual price of energy.

This disinvestment effect (initially observed for the UK by Allan et al, 2007) challenges the argument put forward by Wei (2007) and Saunders (2008) that rebound effects will always be bigger in the long run than in the short run. Wei and Saunders argue that because capital (and labour) are fixed in the short-run, the short-run rebound effect is also constrained. Thereafter, investment will occur (in response to increased marginal productivity of all factors as efficiency improves), allowing the space of production possibilities to expand as the economy adjusts to a long-run equilibrium, and rebound effects to grow. However, this prediction does not hold for all sectors in Allan et al's (2007) analysis for the UK, also using the UKENVI model, or the more detailed sensitivity analyses reported here. Where decreases in actual local energy prices trigger a decline in revenues to the local energy supply sectors this causes a sufficient drop in capital rental rates to stimulate disinvestment (a contraction in capacity) in these sectors. Such a decline in revenues will occur where the general equilibrium price elasticity of demand for energy is sufficiently inelastic that the increase in quantity demanded is less than proportionate to the drop in price. Just as positive investment allows the rebound effect to grow, this contraction in capacity in the energy supply sectors acts to constrain the long-run rebound effect and may lead to rebound being bigger in the short run than in the long run and, in some cases, to the observation of negative rebound effects.

This highlights the role of employing numerical general equilibrium analysis in elucidating the complex economy-wide interactions that underlie rebound effects and the contribution that such analyses can make in developing the theoretical literature. Even though the empirical model used here is at an early stage of development and key variables, such as the equilibrium capital rental rate, have not been empirically verified, having an endogenously determined numerical variable allows us to engage in analytical work to identify key factors that influence the presence and likely direction of important effects such as disenvestment. The example of the capital rental rate/return on capital is an important one: the crucial distinction between the analysis using the 
UKENVI framework employed here and the theoretical work presented by Wei (2007) is that the latter assumes that the return on capital is fixed at unity, whereas in UKENVI it is endogenously determined and affected by changing profitability at the sectoral level. While Wei's (2007) theoretical analysis makes a number of simplifying assumptions, the analysis of the disinvestment effect in the current paper highlights the potential ramifications of this single constraining assumption.

\section{The UKENVI energy-economy CGE model of the UK economy}

The UK model employed here is a variant of the generic AMOSENVI model, the energy-environment variant of the basic AMOS CGE framework developed by Harrigan et al (1991). AMOS is an acronym for A Model of Scotland, deriving its name from the fact the framework was initially calibrated on Scottish data. However, AMOS is a flexible modelling framework, incorporating a wide range of possible model configurations, which can be calibrated for any small open regional or national economy for which an appropriate social accounting matrix (SAM) database exists (for example, in Learmonth et al, 2007, the AMOS framework is applied to the Jersey economy). A condensed description of the AMOSENVI modelling framework is provided in Appendix 1. This section provides a broad overview of the structure of the model.

\subsection{General structure}

UKENVI has 3 transactor groups, namely households, corporations, and government; 25 commodities and activities, 5 of which are energy commodities/supply: coal; oil; gas; renewable and non-renewable electricity (see Figure 1 and Table 1 for details). The UK is modelled as a small open national economy, with a single exogenous external transactor, ROW.

The generic AMOSENVI framework allows a high degree of flexibility in the choice of key parameter values and model closures. However, a crucial characteristic of the model is that, no matter how it is configured, cost minimisation is imposed in production with multi-level production functions, generally of a CES form but with Leontief and Cobb- 
Douglas being available as special cases (see Figure 1). There are four major components of final demand: consumption, investment, government expenditure and exports. In the current application, real government expenditure is assumed to be exogenously determined (but this need not be the case). Consumption is a linear homogeneous function of real disposable income. The external region, ROW, is exogenous, but the demand for domestic exports and imports is sensitive to changes in relative prices between (endogenous) domestic and (exogenous) external prices (Armington, 1969). That is, local and externally produced goods are treated as imperfect substitutes (allowing some deviation between local and external and local commodity prices, even if this is only transitory). Investment is a little more complex as discussed below in Section 3.3.

\subsection{Labour market}

A single local labour market is imposed and characterised by perfect sectoral mobility. Wages are determined via a bargained real wage function in which the real consumption wage is directly related to workers' bargaining power, and therefore inversely to the unemployment rate (Blanchflower and Oswald, 1994; Minford et al, 1994). Here, we parameterise the bargaining function from the econometric work reported by Layard et al (1991):

$$
\mathrm{w}_{\mathrm{L}, \mathrm{t}}=\alpha-0.068 \mathrm{u}_{\mathrm{L}}+0.40 \mathrm{w}_{\mathrm{L}, \mathrm{t}-1}
$$

where: $\mathrm{w}_{\mathrm{L}}$ and $\mathrm{u}_{\mathrm{L}}$ are the natural logarithms of the local real consumption wage and the unemployment rate respectively, $\mathrm{t}$ is the time subscript and $\alpha$ is a calibrated parameter. $^{2}$ Empirical support for this "wage curve" specification is now widespread, even in a regional context (Blanchflower and Oswald, 1994).

\subsection{Capital and investment}

\footnotetext{
${ }^{2}$ Parameter $\alpha$ is calibrated so as to replicate the base period. This calibrated parameter plays no part in determining the sensitivity of the endogenous variables to exogenous disturbances but the initial assumption of equilibrium implied by the calibration procedure is an important one.
} 
Within each period of the multi-period simulations using the UKENVI framework, both the total capital stock and its sectoral composition are fixed, and commodity markets clear continuously. The return on capital is assumed to be equal across all sectors in long-run equilibrium but will vary following a disturbance, depending on changes in revenue and profitability at the sectoral level, until long-run equilibrium is restored. Each sector's capital stock is updated between periods via a simple capital stock adjustment procedure, according to which investment equals depreciation plus some fraction of the gap between the desired and actual capital stock. The desired capital stock is determined on cost-minimisation criteria (and will reflect changing profitability at the sectoral level) and the actual stock reflects last period's stock, adjusted for depreciation and gross investment. The economy is assumed initially to be in long-run equilibrium, where desired and actual capital stocks are equal. This treatment is wholly consistent with sectoral investment being determined by the relationship between the capital rental rate and the user cost of capital. The capital rental rate, or return on capital, is the rental that would have to be paid in a competitive market for the (sector specific) physical capital while the user cost is the total cost to the firm of employing a unit of capital. The interest rate, capital depreciation and tax rates are all taken to be exogenously determined, so that the capital price index is the only endogenous component of the user cost. If the rental rate exceeds the user cost in any one sector, desired capital stock is greater than the actual capital stock, the return on capital will increase in that sector, and there is therefore an incentive to increase capital stock. The resultant capital accumulation puts downward pressure on rental rates and so tends to restore equilibrium (with a new level and composition of the total capital stock in the economy). In the long run, the capital rental rate equals the user cost in each sector, and the risk-adjusted rate of return is equalised between sectors. Interest rates are assumed fixed in international capital markets, so that the user cost of capital varies with the price of capital goods.

The key point to note at this point (and what drives the disinvestment effect introduced above and observed in the case of the domestic energy supply sectors in all of the UK simulations reported in Sections 4 and 5) is that the reverse argument will also hold. If output prices in any sector $i$ fall and the increase in demand for that sector's output do not rise sufficiently to prevent total revenue, and therefore profitability, from falling (i.e. if the general equilibrium demand for sector $i$ output is not sufficiently responsive, or 
elastic, to the drop in price), the return on capital in sector $i$ will decrease. If the return on capital, or capital rental rate drops is less than the user cost, desired capital stock will be less than actual capital stock in sector $i$, providing an incentive to reduce capital stock in that sector. The resultant shedding of capital will put upward pressure on the capital rental rate (and output price) in sector $i$ in order to restore equilibrium. In the long run the capital rental rate will again be equal to the user cost in sector $i$, and the risk-adjusted rate of return on capital will be equalised across sectors, but with a reduced level of capital stock and production capacity in sectors where disinvestment has taken place.

\subsection{Treatment of energy and other inputs to production}

Figure 1 summarises the production structure in each of the 25 sectors in the UKENVI framework. This separation of different types of energy and non-energy inputs in the intermediates block is in line with the general 'KLEM' (capital-labour-energymaterials) approach that is most commonly adopted in the literature. There is currently no consensus on precisely where in the production structure energy should be introduced, for example, within the primary inputs nest, most commonly combining with capital (e.g. Bergman, 1988, Bergman, 1990), or within the intermediates nest (e.g. Beauséjour et al, 1995). Given that energy is a produced input, it seems most natural to position it with the other intermediates, and this is the approach we adopt here. However, any particular placing of the energy input in a nested production function restricts the nature of the substitution possibilities between other inputs. The empirical importance of this choice is an issue that requires more detailed research, which we intend to do as part of the ESRC-funded programme of research of which this paper is part, building on the econometric approach adopted by Kemfert (1998). ${ }^{3}$

\footnotetext{
${ }^{3}$ Note that there is also debate in the CGE literature regarding the use of nested functionalforms because of the imposition of separability assumptions (see Turner, 2002 for a review of this debate). To avoid this problem, Hertel and Mount (1985), Depotakis and Fisher (1988) and Li and Rose (1995) adopt some type of flexible functional form (FFF) production function with dual Generalised Leontief or Translog cost functions. The idea is to make the production function as flexible possible by minimising the number of prior assumptions about its form. In practice, however, this argument over whether to use CES or FFF is likely to boil down to a trade off between flexibility and tractability. In a model with a highly detailed treatment of energy, Naqvi (1998) argues that separability assumptions are necessary from a practical point of view, where there are multiple inputs and/or multiple sectoral outputs. Indeed, as noted by Turner (2002), Hertel and Mount (1985), Depotakis and Fisher (1988) and Li and Rose (1995) all choose to employ two-levels cost functions, with substitution between KLEM inputs on the first level, then within
} 
The multi-level production functions in Figure 1 are generally of constant elasticity of substitution (CES) form, so there is input substitution in response to relative price changes, but with Leontief and Cobb-Douglas (CD) available as special cases. In the applications reported below for both Scotland and the UK, Leontief functions are specified at two levels of the hierarchy in each sector - the production of the non-oil composite and the non-energy composite - because of the presence of zeros in the base year data on some inputs within these composites. CES functions are specified at all other levels.

At present, econometric estimates of key parameter values are not available for the UKENVI model (but, as noted above, this will be the focus of future research, with one aim of the sensitivity analysis reported being the identification key priorities for econometric work). In the base case scenario simulations reported in Section 4, the elasticity of substitution at all points in the multi-level production function is assumed to take the value of 0.3 , apart from where Leontief functions have been imposed and in the case of the electricity composite, a higher value of 5.0 is imposed (to reflect the homogeneity of electricity from different sources and consequent higher degree of substitutability). The Armington trade elasticities are generally set at 2.0, with the exception of exports of renewable and non-renewable electricity, which are set at 5.0, again to reflect the homogeneity of electricity as a commodity in use.

The energy efficiency shock is introduced by increasing the productivity of the energy composite in the production structure of all industries. This procedure operates exactly as in equation (1). It is energy augmenting technical change. The efficiency with which energy is used in the household or government consumption, investment, or export final demand sectors does not change. Moreover, note that under the current production structure in Figure 1, it is only possible to apply the efficiency shock to use of local energy, and not imports. This is an important limitation (see Turner, 2008) and one that will be addressed in future research.

the energy and/or materials aggregates on the second level. Thus, even these authors are in fact prepared to accept some separability assumptions. 


\subsection{Database}

The main database for UKENVI is a specially constructed SAM for the UK economy for the year 2000. This required the initial construction of an appropriate UK InputOutput (IO) table since an official UK analytical table has not been published since the 1995 table in 2002 (National Statistics, 2002). A twenty-five sector SAM was then developed for the UK using the estimated IO table as a major input. The sectoral aggregation is chosen to focus on key energy use and supply sectors. The division of the electricity sector between renewable and non-renewable generation uses an experimental disaggregation provided for Scotland by the Scottish Government IO team. This was then adjusted to reflect the different pattern in electricity generation between the UK and Scotland. Full details on the construction of the UK IO table and SAM are provided in Allan et al (2006).

\section{Impacts of an increase in energy efficiency in the UK economy: base case scenario}

\subsection{Simulation strategy and calculation of rebound effects}

This section presents the results from simulations of an illustrative 5\% exogenous (and costless) increase in energy efficiency in all production sectors in the UK models, where production and trade parameters are specified as outlined in Section 3.4 for the base case scenario. This shock is a one-off step increase in technical efficiency, imposed as an energy-augmenting change to the energy composite. That is to say, in each industry there is a 5\% increase in the efficiency with which the energy composite combines with the non-energy composite to produce the local intermediate composite input (see Figure $1)$.

At this stage it is important to note that introducing consideration of costs involved in introducing an energy efficiency improvement will affect the nature and size of rebound effects (see Allan et al, 2007), as will the precise nature of its introduction. Such issues will be considered in future research in the ongoing project of which this paper is an output. Here, in the first instance, the analysis is more analytical in nature and 
simplified by focussing on an exogenous and costless increase in energy efficiency. This is an important step as it allows us to consider the main basic drivers of the rebound effect (i.e. the general equilibrium responses to reductions in effective, and actual, energy prices) in isolation. However, for a more policy-orientated analysis, future development of the model should include treatment of industry-specific factors and actual policy tools that would be relevant for real policy initiatives. Future research with UKENVI should also allow us to model the impacts of increase energy efficiency in the household sectors, where much policy action may be aimed (for example, with respect to domestic heating).

However, at this stage, for the reasons outlined above, attention is focussed on understanding the basic drivers of the rebound effect and what may intensity or constrain it. We input a 5\% increase in energy augmenting technological progress to all 25 production sectors as in equation (1) to the UKENVI model and calculate rebound as in equation (5). Intermediate inputs of locally supplied energy account for $71.9 \%$ of total UK demand for (UK) electricity and $59.4 \%$ of the demand for (UK) non-electricity energy which give the corresponding values for $\alpha$ when equation (5b) is used to calculate rebound effects (the implication is that the 5\% energy efficiency shock in production equates to a shock affecting $3.6 \%$ of total electricity use and $2.97 \%$ of nonelectricity energy use).

When the efficiency improvement is introduced to the UKENVI models, the resulting changes in key energy and economic variables are reported in terms of the percentage change from the base year values given by the 2000 UK SAM. The economy is taken to be in long-run equilibrium prior to the energy efficiency improvement, so that when the model is run forward in the absence of any disturbance it simply replicates the base year dataset in each period. The reported results refer to percentage changes in the endogenous variables relative to this unchanging equilibrium. All of the effects reported in each case are directly attributable, therefore, to the stimulus to energy efficiency.

\subsection{Simulation results - base case scenario}


Table 2 reports the impacts on key aggregate variables for the central case scenario. Here, the efficiency change is introduced as explained above and the default model configuration and parameter values are used (see Section 3.4). The figures reported are percentage changes from the base year values. Because the economy is taken to be in full (long-run) equilibrium prior to the energy efficiency improvement, the results are best interpreted as being the proportionate changes over and above what would have happened, ceteris paribus, without the efficiency shock. The short and long run time periods in Table 2 are conceptual time periods. In the short-run (the first period after the shock), both labour (population) and capital stocks are assumed to be fixed at the level of individual sectors. In the 'long run' capital stocks have full adjusted fully to their desired sectoral values. ${ }^{4}$

Where we run the model in period-by-period mode, a close adjustment to the long run values will often take a number of years. Here, in the case of the UK, for this particular shock (and base scenario specification), the model begins to converge on long-run values after around 25 periods (with each period interpreted as a year given the annual data used to construct the SAM database).

With wage determination characterised by a bargained wage curve, a beneficial supplyside policy, such as an improvement in energy efficiency, increases employment, reduces the unemployment rate and increase real wages. This has a positive impact on UK economic activity that is generally greater in the long run than in the short run (with the exception of household consumption). In the long run there is an increase of $0.17 \%$ in GDP, $0.21 \%$ in employment and $0.22 \%$ in exports. The expansion is lower in the short run, where GDP increases by $0.11 \%$, where there is a larger increase in consumption but actually a fall in total exports (due to a net rise in output prices in some sectors - e.g. 'Agriculture', 'Construction', 'Communications, Finance and Business' as the price of labour and capital rise - see Figure 2). There is also a drop in total imports. The net effect on imports depends on the strength of the relative price effect (as UK prices fall, imports to production and final consumption activities will fall

\footnotetext{
${ }^{4}$ If we introduce migration of labour between the UK and the rest of the world, population stocks wo uld also update. For example, in our Scottish model (see Hanley et al, 2009, and Turner, 2008) we assume a flow migration function where the supply of labour responds to changes in relative wage and
} 
in favour of locally produced goods) and the stimulus generated by increased economic activity (which will increase UK demand for all local and imported commodities). In the first column of Table 2 the former effect dominates and imports decrease.

However, it is the change in energy use and consequent rebound effects that are of most interest to us here. Table 2 shows that there is a drop in total electricity and nonelectricity energy consumption, but this is less than proportionate to the increase in energy efficiency, with the implication that rebound effects are observed. However, in contrast to the predictions of Wei (2007) and Saunders (2008), outlined above in Section 2.3, the decrease in energy consumption grows over time and we have rebound effects that are smaller in the long run than in the short run. This result also contrasts with those reported for Scotland by Hanley et al (2009) and Turner (2008) for an identical energy efficiency shock, where rebound effects grow over time. The explanation lies in what happens to local energy prices.

Figure 2 shows the short and long run impacts on UK output prices of the $5 \%$ increase in energy augmenting technological progress. For each sector this will reflect the net effect of changes in costs of production (capital rental rates, nominal wages, price of energy and non-energy intermediates) as well as the demand-side response. Figure 2 shows that, while output prices generally fall across the board, in some sectors the price rises initially (due to the increased price of labour and capital rental rates while capacity is constrained). The largest fall in output prices is observed in the more energy-intensive energy supply sectors. Note that what is happening here is, since we have local production of energy, actual as well as effective energy prices fall. The system-wide response to the drop in both effective and actual energy prices acts to offset the engineering or pure efficiency effect of the initial disturbance. Figure 3 shows that the output of the all five UK energy supply sectors falls in the short run as less energy is required in the production of output in other sectors. That is, while final consumption of oil, coal, gas and electricity rises as prices fall, the efficiency effect that is taking place in intermediate demand causes a net reduction in the demand for UK energy. In the case of Scotland, Turner (2008) found that falling energy prices, particularly in the electricity sectors, stimulate export demand for the outputs of the Scottish energy supply sectors to 
such an extent that competitiveness effects quickly dominate the negative impacts of the efficiency effect. However, with the exception of Oil (which exported almost $30 \%$ of its output in our base year of 2000), the UK the energy supply sectors are not heavily traded relative to their Scottish counterparts (each of the other four exporting less than $2 \%$ of their output) and therefore positive competitiveness effects are of little importance relative to the efficiency effect in the short-run. Crucially, the lack of export demand for the outputs of the UK energy supply sectors means that the net price elasticity of demand for the outputs of these sectors is relatively inelastic. This manifests in Figure 2, where we see a relatively large drop in short run output prices, particularly in the two electricity sectors (simple supply and demand theory shows us that price drops by more the more inelastic the declining demand). The long-run drop in local energy prices is smaller than in the short run and output in these sectors remains below base year levels. The opposite is true in the corresponding Scottish simulations reported by Turner (2008), where more conventional rebound effects are observed.

The key factor driving the short and long run rebound and energy supply sector results observed for the UK in Table 2 is the fact that falling local energy prices trigger the disinvestment effect introduced in Section 2.3 above. The simultaneous net decline in price and demand causes profitability in the UK energy supply sectors to fall such an extent that disinvestment occurs - i.e. firms begin to run down their capital stocks. As profitability falls, the return on capital (in these relatively capital-intensive industries) decreases (see Figure 4), and this triggers disinvestment and a contraction in capacity (see Figure 5). In order to halt the disinvestment and reach a new equilibrium (with a lower capital stock) prices have to begin rising again (see Figure 6) to allow the return on capital to be restored at a rate equal to the user cost of capital (see Section 3.3). This rise in local energy prices will in turn limit the size of the substitution, composition, output and income effects that drive rebound effects as the economy adjusts. For this reason, in the second column of Table 2 we observe that the drop in both electricity and non-electricity consumption are larger and the associated rebound effects are smaller in the long run that they are in the short run.

This is perhaps the crucial finding in this paper, and one that contrasts with Wei's (2007) and Saunder's (2008) argument that the long-run rebound effect will always be bigger than the short-run rebound effect because capital (and labour) are fixed in the 
short-run (constraining the rebound effect), but thereafter investment will occur (in response to increased marginal productivity of all factors as efficiency improves), expanding the space of production possibilities. Here this prediction does not hold in all sectors because the reduction in profitability as output prices fall in energy supply sectors (particularly electricity supply) causes a sufficient drop in capital rental rates to stimulate disinvestment (a contraction in capacity) in these sectors, which in turn constrains the long-run rebound effect. The crucial distinction between the empirical general equilibrium framework employed here and the theoretical one presented by Wei (2007), which gives rise to the argument of a universal increase in capacity (and rebound effects that are bigger in the long run than in the short run), is that Wei's model assumes that the return on capital is fixed at unity, whereas here it is endogenously determined and affected by changing profitability.

\section{Sensitivity analysis}

\subsection{Simulation strategy for sensitivity analysis}

Of course, as explained in Section 3.4, in the lack of firm empirical evidence to inform key parameter values that are likely to be important in determining the nature of rebound effects, these have to be informed by the modeller's judgement. In such circumstances, sensitivity analysis is essential. Allan et al (2007) does conduct some sensitivity analysis for the UK case examined above. For the Scottish case cited above, Hanley et al (2009) similarly conduct limited sensitivity analyses, where their main finding is that the specification of the price elasticities of RUK export demand for Scottish electricity is the key parameter with respect to the strength of rebound and presence of backfire effects. On the other hand, Allan et al (2007) conclude that the UK results are most sensitive to elasticities of substitution in production (particularly between the energy and non-energy composites). The relative importance of production over trade parameters for the UK would be expected, since this is a national economy (of which Scotland is part) with more limited external trade, particularly in energy. Allan et al's (2007) and Hanley et al's (2009) sensitivity analyses were not limited to 
parameter values in production and trade, but this is where some of the most interesting results are found.

The main objective of the current paper is to conduct a more systematic sensitivity analysis of the influence of these two groups of parameters on the UK results reported above. The intention is not to try and determine what the correct parameter values are for either model, or to give more accurate estimates of rebound effects for the UK. Rather, given that the underlying cause of rebound effects is what happens to prices in the system, and that the suggestion in previous work in Allan et al (2007) and Hanley et al (2009) has been that rebound effects will occur even where key elasticities of substitution in production are set close to zero, the intention here is to investigate just how much price sensitivity in production and/or trade is required to induce the type of results observed so far. Therefore, this section of this paper is devoted to carrying out a systematic sensitivity analysis, where relative price sensitivity via the production and trade parameters is gradually increased the UK model.

The sensitivity analysis involves running the matrix of simulations shown in Table 3. Down each column, trade parameters (imports in both production and final consumption and exports from production) are held constant at the values shown at the top of the column while all parameters in production are varied as shown on the left of the grid, and vice versa along each row. The simulations are run as multi-period simulations, but, given the number of simulations involved, Table 4 reports only the short run (first period/year after the shock) and long run (when the economy has fully adjusted) rebound results for the UK. Moreover, as the results are qualitatively similar, we focus our attention on non-electricity energy consumption. A fuller set of results, including corresponding sensitivity analyses for Scotland are reported in Turner (2008).

Note that the initial intention was to use Leontief functional forms to represent the case of zero elasticity and Cobb Douglas to represent unitary elasticity (CES is unstable with an elasticity values of 0 and 1). However, the initial simulation runs in these cases (with the exception of Cobb Douglas for the trade parameters) either would not solve or gave results with huge backfire effects where these would not be expected (this may reflect 
the arguments put by Saunders, 2008, regarding appropriate functional forms for estimating rebound in a partial equilibrium context). Therefore, as indicated in Table 4 for the zero elasticity/Leontief case, we have instead used CES with the smallest positive value that would allow the models to solve for production (0.064) and trade $(0.3) .^{5}$ In the Cobb-Douglas/unitary elasticity case, CES is used with the elasticity value set at 0.999999 in the case of production. However, Cobb-Douglas is retained for unitary trade elasticities, as this appears to give sensible results (Sanders's, 2008, arguments about Cobb-Douglas resulting in unrealistically high rebound effects are only made in the case of production functions).

\subsection{The relative size of short run and long run rebound effects}

We examine the results in Table 4 in the context of the key issues identified above. First, in Section 4, we observed rebound effects that were bigger in the short run than in the long run. This was caused by a disinvestment effect and ran contrary to the theoretical predictions of Wei (2007) and Saunders (2008). If we consult Table 4 we see that this is not a general result. The shaded cells in Table 4 show cases where rebound is bigger in the short-run than in the long run but unshaded cells indicate cases where the opposite is true. However, disinvestment is still present in this latter set of cases: here the short run rebound effect is also constrained, by weak competitiveness effects where export demand is highly inelastic, a point to which we return below. The disinvestment effect occurs in most of the UK simulations reported in Table 4, only disappearing for all of the non-electricity energy supply sectors in simulations 126, 139, 140, 152, 153 and 154 (see simulation identifier in Table 3), where both trade and production are highly price elastic. However, the electricity disinvestment effect does not disappear at all in the UK simulations reported here and this is what continues to dampen the longrun non-electricity energy rebound effect in the six simulations identified above. Given the contraction in capacity in the non-renewable electricity supply sector (and lower demand for its outputs given a declining drop in the price of output) the increased demand of this sector (which is the biggest individual user of the non-electricity energy)

\footnotetext{
${ }^{5}$ Leontief technology is retained in the two nests of the production function in Figure 1 - production of the non-oil and non-energy composites - where the presence of zeros in the SAM database mean that CES functions cannot be used.
} 
for the outputs of the three non-electricity sectors is smaller in the long run that in the short run.

The disinvestment effect is not peculiar to the UK economy. Turner (2008) shows that disinvestment effects do occur in the Scottish case as well. If we label the unshaded and shaded areas in Table 4 as A and B respectively, the schematic in Figure 7, which reflects Turner's (2008) qualitative results for non-electricity rebound in the Scottish case, shows that where trade elasticities are set at 1.1 or lower, disinvestment also constrains long-run rebound in the corresponding Scottish simulations. In both Scotland and the UK, the base case scenarios discussed in Section 4 above, lie toward the upper right hand side of the grid. However, differences in the structure of the two economies, particularly with respect the trade in energy, mean that the magnitude of the disinvestment effect differs as we move along each row (holding production elasticities constant while trade elasticities grow). In both Scotland and the UK, the disinvestment effect lessens as trade (particularly export demand) becomes more price elastic (though import demand will also be important as, with external prices determined exogenously, increased substitution in favour of imports will limit the drop in output prices and profitability). In the case of Scotland, the depressing effect of disinvestment on long run rebound begins to disappear after trade elasticities reach unity and we have an additional area of the grid in Figure 7 where the net impact is bigger rebound in the long run than in the short run. However, in the UK, which is a relatively less open economy (again, particularly with respect to energy supply), the dampening effect of disinvestment on long run rebound persists throughout the grid, only beginning to disappear in the case of the non-electricity energy supply sectors in the last three columns of Table 4 (but only in cases where production parameters are also elastic).

Recall that the disinvestment effect occurs because output prices in the energy supply sectors in particular (which also tend to be highly energy intensive sectors) drop in response to the increase in energy efficiency. The lower the price elasticity of demand for energy (due in Table 4 and Figure 7 to low substitution elasticities in production and low Armington price elasticities of export demand and/or the initial level of external demand), price drops further and profitability falls so much that capital rental rates (the return on capital) collapse and disinvestment occurs. Where the trade parameters are set at less than 1 , there are a number of cases where there is actually a negative terms of 
trade effect in the UK economy, with a decrease in GDP, employment and consumption (see Table 5). In these case the increase in energy efficiency actually manifests itself as a negative supply shock due to the collapse in local energy supply prices. Turner (2008) shows that this also happens in the comparable Scottish simulations. Indeed note that in Tables 4 and 5 there are some simulations - marked with an asterix - where the negative supply effect is so extreme that the UKENVI model fails to solve for a new equilibrium. Note also that in Figure 7 there are two additional columns in the Scottish case, where trade parameters are set to 0.064 and 0.1 : the UK model would not solve at all for these cases. This negative effect is greater the higher the production elasticities are set (i.e. as we read down the columns), because here the system responds to the drop in energy prices by using more energy in production throughout the economy, while the drop in output prices (i.e. the positive competitiveness effect) lessens the more elastic is intermediate demand for energy. Thus we observe very large rebound, and sometimes backfire, effects accompanying a contraction in aggregate economic activity (backfire is possible even in the presence of disinvestment in the UK energy supply sectors due to the efficiency improvement).

In terms of the relative strength of short and long run effects, as noted above, we have identified an area (labelled $A$ in the schematic in Figure 7) where a reversal of this relationship occurs, still in the presence of disinvestments, but in cases where inelastic trade parameters combine with more elastic production parameters. This reversal is again explained by what happens with prices and the impact on competitiveness in the short-run. As in the shaded area B, disinvestment constrains the long-run rebound effect. However, in the columns where trade parameters are set at very low values, this means that export demand is highly inelastic. This constrains the positive competitiveness effect and, consequently, the short-run rebound effect. As export demand becomes more elastic, the short-run rebound effect grows overtaking the growth of the long-run effect (which is still depressed by disinvestment) in the shaded area of the grid. This is slower to happen the higher the production parameter values as more elastic intermediate demand for energy limits the fall in prices that stimulates the competitiveness effect. This limits the short-run response in export demand, which in turn negatively impacts the positive supply side effects expected from an efficiency improvement (the increase/decrease in GDP becomes smaller/larger as we read down 
the columns with low trade elasticities in the short run grid in Table 5) and limits the size of the short run rebound effect.

\subsection{Presence of backfire effects}

Allan et al's (2007) more limited sensitivity analysis for the UK notes that backfire (i.e. rebound greater than 100\%) does not occur in the UK case. However, examination of Table 4 again shows that this is not a general result. In a large number of cases, backfire effects actually occur in both the short and long run (Turner, 2008 shows that this is also the case for electricity rebound effects). However, the presence of backfire effects is only observed in Table 4 in cases where elasticities of substitution in production are greater than 1. As shown by Saunders (2008), for CES functions, backfire require that the elasticity of substitution be greater than 1 minus the physical energy input share. Given that the energy share is typically small the finding in Table 4 is consistent with Saunders (2008) partial equilibrium analysis. It also demonstrates the importance of elasticities of substitution in production in determining the general equilibrium pirce elasticity of demand for energy. Remember from the theoretical exposition in Section 2.1 that there four important ranges of the general equilibrium price elasticity of demand for energy. If this lies between zero and unity there would be a fall in energy use but some rebound effect, though not backfire, which would require that the general equilibrium price elasticity of demand for energy is equal to or greater than unity. The results in Table 4 are consistent with this conclusion (and Turner, 2008, shows that this is also the case for UK electricity rebound and in the Scottish case). While, the two sets of parameters examined in the sensitivity analysis do not tell the whole story (factors such as the elasticity of supply of other factors of production and income elasticities of energy demand will also contribute), the fact that (even where trade parameters are inelastic) backfire occurs when production parameters are raised to unity (or just over unity) implies that elasticities of substitution in production are very important drivers of rebound effects in the UK.

\subsection{Presence of 'negative rebound' effects}


Another interesting result in the long run grid of Table 4 is the apparent occurrence of negative rebound results. That is, we have proportionate decreases in total energy consumption that are greater than the proportionate increase in energy efficiency. Saunders (2008) discusses the possibility of 'super-conservation', which he explains is a counter-intuitive result ("How can, say, a $1 \%$ increase in fuel efficiency result in a $2 \%$ decline in fuel use?", Saunders, 2008, p.20). The UKENVI model does not incorporate any of the production function specifications found by Saunders (2008) to give such results. The negative rebound effects observed here arise from a different sourece. Here it is the effects of falling (actual and effective) energy prices that lead to further reductions in energy use. We have already seen that falling energy prices may in fact reduce profitability to such an extent as to trigger disinvestment, which will act to constrain rebound effects. This is not an energy saving/conservation in response to the change in efficiency as such - it is a general equilibrium response to falling profitability, factor returns and incomes. In this section we explore what underlies the observations of long run negative rebound effects in Table $4 .^{6}$

One factor that may put downward pressure on rebound effects is the impact of falling incomes in the household sector where direct and derived elastcities of demands for labour are very low. For example, Learmonth et al (2007) find that in cases where very low elasticities of substitution in production combine with highly inelastic export demands, the direct and derived demand for labour falls to such an extent that energy use and pollution generation in the household sector actually decrease as output and employment rise in all sectors of the economy rise. This is a result of reduced real household income and expenditure. Therefore, in Table 6, household consumption of energy is removed from the calculation of rebound effects using equation (5b) in all cases where long run negative non-electricity energy rebound effects are found in Table 4. That is, the rebound effects in Table 6 focus on the intermediate or production rebound effect (where no boundary adjustment is required to equation (5). Turner (2008) finds that this has may have either positive and negative impacts on the rebound effects, depending on (a) whether household income actually falls; (b) if it does, whether falling household consumption leads to a shift in favour of expenditure on local goods (given the decrease in local output prices) or a decrease in consumption of both

\footnotetext{
${ }^{6}$ Turner (2008) also finds some occurrences of short run negative rebound effects where trade parameters
} 
local and imported goods. However, comparing the results in Tables 4 and 6 we can see that, in the case of the UK non-electricity energy rebound effects for these simulations, removing household income further depresses the negative rebound effects observed in Table 4, and actually leads to two additional cases on the right of the second row in Table 6.

Therefore, while household income and consumption effects offer some explanation for the negative rebound effects in Table 4, the fuller explanation must lie in the production sectors that have been targeted with the shock. The question, then, is whether this is due to additional energy savings triggered by the efficiency improvement or price effects within the system

Hanley et al (2009) carry out sensitivity analysis in terms of which sectors the energy efficiency improvement actually takes place in. They find that when they target only the energy supply sectors the rebound effects grow significantly. The energy intensity of production in the energy supply sectors offers a partial explanation. However, a key issue is the huge positive competitiveness effects driving rebound when the energy supply sectors, particularly the electricity sectors, are directly targeted. When the shock is targeted only at the other 20 energy use sectors, rebound effects decrease dramatically. Table 7 shows the results of similarly targeting the efficiency shock in the UK case (for the base case scenario model configuration) only at the 20 non-energy supply sectors (sectors 1-20 in Table 1). Note that this changes the calculation of the rebound effect using equation 5(b) as intermediate inputs of locally supplied energy to the non-energy supply sectors account for just $29 \%$ of total UK demand for (UK) electricity and $30.6 \%$ of the demand for (UK) non-electricity energy (so that the 5\% energy efficiency shock in production equates to a shock affecting $1.45 \%$ of total electricity use and $1.53 \%$ of non-electricity energy use).

As in Hanley's (2009) results for Scotland, in comparing Tables 2 and 7 we can see that rebound effects are smaller when the energy supply sectors themselves are not targeted. Indeed, in Table 7 a negative long-run electricity rebound effect is observed (the long-

are highly inelastic. 
run drop in total electricity consumption is greater than the effective $1.45 \%$ increase in energy efficiency when only the non-energy supply production sectors are targeted with the shock).

In order to further examine whether breaking down the shock in this way helps us to understand the occurrence of negative rebound effects, let us take the most extreme, price inelastic scenario and largest non-electricity energy negative rebound effect observed in Table 4. This is simulation 6, with unitary elasticity (Cobb Douglas technology) in trade and all production parameters set at 0.064. Table 8 shows the results of targeting the energy efficiency shock at the 20 non-energy supply sectors. Negative rebound effects are observed for both types of energy consumption in the long run and these are larger than those reported for the base case scenario given more inelastic production and trade parameters. However, this is not due to additional energy conservation in the energy use sectors as a direct result of the change in efficiency itself. If we examine Figure 8, we see that the short run drop in non-electricity energy consumption is proportionately less than the 5\% efficiency improvement within in each of the 20 production sectors targeted with the shock (the denominator of equation [5b] is the full $5 \%$ when calculating the sector-specific rebound effect).

The source of the long-run economy-wide negative rebound effect is what happens in the five energy supply sectors, which account for just under $30 \%$ of the long run reduction in non-electricity energy use. There are several causes and effects of what happens in the energy supply sectors. First, there is a net decrease in demand for energy as an input to production in the other 20 energy use sectors, with the pure efficiency effect only slightly offset by positive substitution and competitiveness effects, given that intermediate and final demands are both highly price inelastic. Second, despite the very inelastic direct and derived demand for labour in this simulation, there is actually an increase real household income and expenditure, including expenditure on all local goods and services (but a decrease in imports). However, this is a very small increase (only $0.1 \%$ in the long run). Third, there are negative multiplier effects in the energy supply sectors themselves as these (relatively energy-intensive) sectors reduce their own 
intermediate demand for energy inputs in response to the demand contractions elsewhere in the economy.

All of these factors will effect the size of rebound in both the short and long run. However, in terms of the long run rebound effect reported in Table 8, the key contributory factor is the disinvestment effect. While export demand for UK energy does grow slightly in response to falling prices in the energy supply sectors, the net contraction in what is already very inelastic demand causes prices to drop proportionately more than output so that there is a decline in revenue and profitability. This causes capital rental rates to collapse in the relatively capital-intensive energy supply sectors, triggering the disinvestment effect, which is a key contributory factor to the long run negative rebound effect observed here (capital stocks decrease by between $1.1 \%$ in the Gas sector and $2.1 \%$ in the electricity sectors over the long run)

\section{Summary and conclusions}

While the empirical analysis presented here is specific to the case study of the UK, and limited by problems of data availability and reliability, the observation and explanation of disinvestment effects that act to dampen long run rebound effects is perhaps the key contribution of this paper. The disinvestment effect will have more general significance in analysis of energy efficiency improvements in economies where there is domestic supply of energy. It may also be applicable at the global level where, despite OPEC's command of marginal supply, downward demand pressures do exert downward pressure on prices. ${ }^{7}$

The results presented here show that the disinvestment effect is a necessary, but not sufficient, condition for rebound effects to be bigger in the short run than in the long run (as short run rebound may also be dampened by negative competitiveness effects), a result that runs counter to the theoretical predictions of Wei (2007) and Saunders (2008). One crucial difference between the theoretical general equilibrium analysis presented by Wei (2007), which underlies the predictions of Saunders (2008) also, and

\footnotetext{
${ }^{7}$ I am grateful to an anonymous referee for making this point.
} 
the empirical general equilibrium analysis presented here is whether the return on capital, or capital rental rate, is fixed (as in Wei's model) or endogenously determined (as in the UKENVI model here). Where the return on capital is endogenous it will be negatively affected by falling profitability and lead to a contraction in capital stock in the affected (energy supply) sectors, even through aggregate investment and productive capacity at the economy-wide level is likely to rise in response to a positive supply shock such as an increase in efficiency in one of the factors of production.

However, given that the results reported here have been shown to be sensitive to elements of model specification (including the treatment of imported energy - see Turner, 2008) and the quality of data to construct the base year SAM, further research is required. In terms of model development, a key point of debate in the energy literature more generally has been the specification of production functions and, in particular, the substitutability of capital for energy, including issues of capital vintage and homogeneity. Given the importance of disinvestment effects in the results presented here, the treatment of capital is likely to be of crucial importance. Therefore, the next step in the programme of research of which this paper is part will be to introduce a wider set of possible model configurations and investigate the sensitivity of rebound results to alternative specifications. Another important activity will be to attempt to empirically estimate key elasticities in production and trade, and other factors that influence the general equilibrium price elasticity of demand for energy, as well as attempting to model more 'realistic' and policy relevant scenarios (i.e. relaxing the assumption of a costless and exogenous improvement in energy augmenting technological progress). In the UK case in particular, the analysis here suggests that econometric estimation of nested KLEM production functions and elasticities of substitution therein, in likely to be a crucial development for the UKENVI model, perhaps following the approach proposed by Kemfert (1998).

\section{Acknowledgements}

The research reported here has been funded by the ESRC through the First Grants Initiative (Grant reference RES-061-25-0010). However, this research builds on 
previous and related research funded by the EPSRC through the SuperGen Marine Energy Research Consortium (Grant reference: EP/E040136/1). An earlier version of this paper was presented as a keynote speech at the International Input Output Association Meeting on Managing the Environment in Seville, Spain, July 2008. I am grateful to participants at this conference, and subsequent seminars at the Universities of Strathclyde, Stirling and Newcastle their valuable comments and feedback, and also to Steve Sorrell at the UK Energy Research Centre (UKERC) and Harry Saunders (Decision Processes Incorporated, California) for comments and advice which have helped develop the work reported here. I am grateful to two anonymous referees who responded to the initial submission of this paper with very helpful suggestions and comments that I feel have strengthened this paper significantly. I am also indebted to my colleagues on the regional and energy modelling teams at the Fraser of Allander Institute, Department of Economics at the University of Strathclyde, namely Peter McGregor, Kim Swales and Grant Allan for their ongoing work on developing the AMOSENVI modelling framework employed here. I am further indebted to the aforementioned colleagues, and to Nick Hanley, Department of Economics, University of Stirling, as my co-authors on previous work investigating rebound effects in Scotland and the UK, work that the research reported here builds upon. Finally, I would like to thank Amanda Lim and Janine De Fence for their very valuable research assistance in running and reporting the numerous simulations required for this paper.

\section{References}

Allan, G., N.D. Hanley, P.G. McGregor, J.K. Swales and K.R. Turner (2006), 'The Macroeconomic Rebound Effect and the UK Economy', Final Report to DEFRA, May 2006.

Allan, G.J., Hanley, N.D., McGregor, P.G., Swales, J.K. and Turner, K.R. (2007) The impact of increased efficiency in the industrial use of energy: a computable general equilibrium analysis for the United Kingdom, Energy Economics, 29, pp. 779-798. 
Allan, G.J., Gilmartin, M., McGregor, P.G., Swales, J.K. and Turner, K.R., (2008a), Modelling the economy-wide rebound effect, in Energy Efficiency and Sustainable Consumption: The Rebound Effect, Palgrave MacMillan.

Allan, G.J., Gilmartin, M., McGregor, P.G., Swales, J.K. and Turner, K.R., (2008b), Economics of energy efficiency, in J. Evans and L.C. Hunt, eds, Intemational Handbook of Energy Economics, Edward Elgar, Cheltenham, UK, forthcoming.

Armington, P. (1969), A theory of demand for products distinguished by place of production, IMF Staff Papers, 16, pp. 157-178.

Beauséjour, L., Lenjosek, G., and Smart, M. (1995) A GCE Approach to Modelling Carbon Dioxide Emissions Control in Canada and the United States, The World Economy, 18, pp.457-489.

Bergman, L. (1988) Energy Policy Modelling: a Survey of General Equilibrium Approaches, Journal of Policy Modelling, 10, pp.377-399.

Bergman, L. (1990) Energy and Environmental Constraints on Growth: a CGE Modelling Approach, Journal of Policy Modelling, 12, pp.671-691.

Bergman, L. (2005) CGE Modelling of Environmental Policy and Resource Management, Chapter 24 in Mäler and Vincent (eds) Handbook of Environmental Economics, Volume 3: Economywide and Intemational Environmental Issues, Elsevier, North Holland.

Birol, F. and Keppler J. H. (2000) Prices, technology development and the rebound effect, Energy Policy, 28, pp. 457-479.

Blanchflower, D.G. and Oswald, A.J. (1994), The Wage Curve, M.I.T. Press, Cambridge, Massachusetts. 
Böhringer, C. and Rutherford, T. (1997) Carbon Taxes with Exemptions in an Open Economy: a General Equilibrium Analysis of the German Tax Initiative, Journal of Environmental Economics and Management, Vol.32, pp.189-203.

Broadstock, D., Hunt, L. and Sorrell, S. (2007) Evidence from elasticity of substitution studies, in Sorrell, S. (ed) The Rebound effect: an assessment of the evidence for economy-wide energy savings from improved energy efficiency. UK Energy Research Centre.

Link: http://www.ukerc.ac.uk/Downloads/PDF/07/0710ReboundEffect/0710Techreport3.pdf.

Brookes, L. (1990) The greenhouse effect: the fallacies in the energy efficiency solution, Energy Policy, 18, pp. 199-201

Conrad, K. (1999) Computable General Equilibrium Models for Environmental Economics and Policy Analysis, in J.C.J.M. van den Bergh ed. Handbook of Environmental and Resource Economics, Edward Elgar Publishing Ltd, 1999.

Despotakis, K.A. and A.C. Fisher (1988) Energy in a Regional Economy: a Computable General Equilibrium Model for California, Journal of Environmental Economics and Management, 15, pp.313-330.

Dufournaud, C.M., Quinn, J.T. and Harrington, J.J. (1994) An applied general equilibrium (AGE) analysis of a policy designed to reduce the household consumption of wood in the Sudan, Resource and Energy Economics, 16, pp.69-90.

Glømsrod, S. and Taojuan, W. (2005) Coal cleaning: a viable strategy for reduced carbon emissions and improved environment in China?, Energy Policy, 33, pp.525-542.

Grepperud, S. and Rasmussen, J. (2004) A general equilibrium assessment of rebound effects, Energy Economics, 26, pp.261-282.

Hanley ND, McGregor PG, Swales JK, Turner KR. (2006) The impact of a stimulus to energy efficiency on the economy and the environment: A regional computable general equilibrium analysis. Renewable Energy, 31; pp.161-171 
Hanley ND, McGregor PG, Swales JK, Turner KR. (2009) Do increases in energy efficiency improve environmental quality and sustainability?, Ecological Economics, 68, pp.692-709.

Harrigan, F., P. McGregor, R. Perman, K. Swales and Y. Yin (1991), AMOS: A MacroMicro Model of Scotland, Economic Modelling, 8, pp. 424-479.

Herring, H. (1999) Does energy efficiency save energy? The debate and its consequences, Applied Energy, 63, pp. 209-226.

Herring, H. (2006), 'The Macro-Economic Rebound Effect and the UK Economy', Final Report to DEFRA, May 2006.

Hertel, T.W. and T.D. Mount (1985) The Pricing of Natural Resources in a Regional Economy, Land Economics, 61, pp.229-243.

House of Lords (2005) Energy efficiency, science and technology committee, $2^{\text {nd }}$ report of session 2005-06, Volume 1 report. The Stationary Office: London; 2005.

Jevons, W.S. (1865) The coal question - can Britain survive?, first published in 1865, reprinted by MacMillan in 1906. (Relevant extracts appear in Environment and Changes, February, 1974)

Kemfert, C. (1998) Estimated substitution elasticities of a nested CES production function approach for Germany, Energy Economics, 20, pp. 249-264.

Khazzoom, D.J. (1980) Economic implications of mandated efficiency in standards for household appliances, Energy Journal, 1, pp. 21-39.

Learmonth, D., P.G. McGregor, J.K. Swales, K.R. Turner and Y.P. Yin (2007), The importance of the regional/local dimension of sustainable development: An illustrative 
Computable General Equilibrium analysis of the Jersey economy, Economic Modelling, 24, pp. 15-41.

Lee, H. and D.W. Roland-Holst (1997) Trade and the environment, in J.F. Francois and K.A, Reihert eds. Applied Methods for Trade Analysis: a Handbook, Cambridge University Press.

Li, P. and A. Rose (1995) Global Warming Policy and the Pennsylvania Economy: A Computable General Equilibrium Analysis, Economic Systems Research, 7, pp.151171.

Minford, P., Stoney, P., Riley, J. and Webb, B. (1994), An econometric model of Merseyside: validation and policy simulations, Regional Studies, 28, pp. 563-575.

Naqvi, F. (1998) A computable general equilibrium model of energy, economy and equity interactions in Pakistan, Energy Economics, 20, pp. 347-373.

National Statistics 2002. United Kingdom Input-Output Analytical Tables, 1995. Web edition, download at http://www.nationalstatistics.gov.uk.

Saunders, H.D. (1992) The Khazzoom-Brookes Postulate and Neoclassical Growth, The Energy Journal, 13, pp.131-148.

Saunders, H.D. (2000a) A view from the macro side: rebound, backfire and KhazzoomBrookes, Energy Policy, 28, pp. 439-449.

Saunders, H.D. (2000b) Does predicted rebound depend upon distinguishing between energy and energy services?, Energy Policy, 28, pp. 497-500.

Saunders, H.D. (2008), "Fuel conserving (and using) production functions", forthcoming in Energy Economics, doi:10.1016/j/eneco.2007.11.006. 
Schipper, L. (ed) (2000) On the rebound: the interaction of energy efficiency, energy use and economic activity, The Energy Journal (Special Issue), 28, pp. 6-7.

Semboja, H.H.H. (1994). The effects of an increase in energy efficiency on the Kenyan economy, Energy Policy, 22, pp.217-225.

Sorrell, S. (2007), The rebound effect: an assessment of the evidence for economy-wide energy savings from improved energy efficiency, Report produced by the UK Energy Research Centre. Dowload report at:

http://www.ukerc.ac.uk/Downloads/PDF/07/0710ReboundEffect.

Turner, K. (2002), Modelling the impact of policy and other disturbances on sustainability policy indicators in Jersey: an economic-environmental regional computable general equilibrium analysis, Ph.D. thesis, University of Strathclyde.

Turner, K. (2008), A computable general equilibrium analysis of the relative price sensitivity required to induce rebound effects in response to an improvement in energy efficiency in the UK economy, Strathclyde Discussion Papers in Economics, No. 08-07.

Wei, T. (2007), Impact of energy efficiency gains on output and energy use with CobbDouglas production function, Energy Policy, 35, pp. 2023-2030.

Wissema, W. and R. Dellink (2007), AGE analysis of the impact of a carbon energy tax on the Irish economy, Ecological Economics, 61, pp.671-683. 
Appendix 1. A condensed version of the UKENVI framework

\begin{tabular}{|c|c|}
\hline (1) Gross Output Price & $p q_{i}=p q_{i}\left(p v_{i}, p m_{i}\right)$ \\
\hline (2) Value Added Price & $p v_{i}=p v_{i}\left(w_{n}, w_{k, i}\right)$ \\
\hline $\begin{array}{l}\text { (3) Intermediate Composite } \\
\text { Price }\end{array}$ & $p m_{i}=p m_{i}(p q)$ \\
\hline (4) Wage setting & $w_{n}=w_{n}\left(\frac{N}{L}, c p i, t_{n}\right)$ \\
\hline (5) Labour force & $L=\bar{L}$ \\
\hline (6) Consumer price index & $c p i=\sum_{i} \theta_{i} p q_{i}+\sum_{i} \theta_{i}^{\text {ROW }} \overline{p q}^{\text {ROW }}$ \\
\hline (7) Short-run capital supply & $K_{i}^{s}=\bar{K}_{i}^{s}$ \\
\hline (8) Long-run capital rental & $w_{k, i}=u c k(k p i)$ \\
\hline (9) Capital price index & $k p i=\sum_{i} \gamma_{i} p q_{i}+\sum_{i} \gamma_{i}{ }^{\text {ROW }} \overline{p q_{i}}{ }^{\text {ROW }}$ \\
\hline (10) Labour demand & $N_{i}^{d}=N_{i}^{d}\left(V_{i}, w_{n}, w_{k, i}\right)$ \\
\hline (11) Capital demand & $K_{i}^{d}=K_{i}^{d}\left(V_{i}, w_{n}, w_{k, i}\right)$ \\
\hline (12) Labour market clearing & $N^{s}=\sum_{i} N_{i}^{d}=N$ \\
\hline (13) Capital market clearing & $K_{i}^{s}=K_{i}^{d}$ \\
\hline (14) Household income & $Y=\Psi_{n} N w_{n}\left(1-t_{n}\right)+\Psi_{k} \sum_{i} w_{k, i}\left(1-t_{k}\right)+\overline{\bar{T}}$ \\
\hline (15) Commodity demand & $Q_{i}=C_{i}+I_{i}+G_{i}+X_{i}+R_{i}$ \\
\hline
\end{tabular}




\begin{tabular}{|l|c|}
\hline (16) Consumption Demand & $C_{i}=C_{i}\left(p q_{i}, \bar{p} q_{i}^{R O W}, Y, c p i\right)$ \\
\hline (17) Investment Demand & $I_{i}=I_{i}\left(p q_{i}, \bar{p} q_{i}^{R O W}, \sum_{i} b_{i, j} I_{j}^{d}\right)$ \\
\hline$I_{j}^{d}=h_{j}\left(K_{j}^{d}-K_{j}\right)$
\end{tabular}

\section{NOTATION}

\section{Activity-Commodities}

$\mathrm{i}, \mathrm{j}$ are, respectively, the activity and commodity subscripts (There are twenty-five of each in UKENVI, see Table 1)

\section{Transactors}

ROW $=$ Rest of World

\section{Functions}

pm (.), pq(.), pv(.) CES cost function

$\mathbf{k}^{\mathbf{S}}(),. \mathbf{w}($.$) \quad Factor supply or wage-setting equations$

$\mathbf{K}^{\mathrm{d}}(),. \mathbf{N}^{\mathrm{d}}(),. \mathbf{R}^{\mathrm{d}}($.$) \quad CES input demand functions$

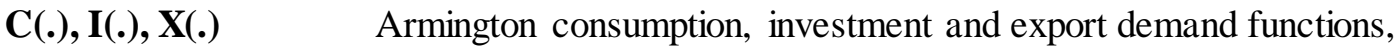
homogenous of degree zero in prices and one in quantities

uck User cost of capital

Variables and parameters

C

consumption 


\begin{tabular}{|c|c|}
\hline D & exogenous export demand \\
\hline G & government demand for local goods \\
\hline I & investment demand for local goods \\
\hline $\mathbf{I}^{\mathbf{d}}$ & investment demand by activity \\
\hline $\mathbf{K}^{\mathbf{d}}, \mathbf{K}^{\mathbf{S}}, \mathbf{K}$ & capital demand, capital supply and capital employment \\
\hline $\mathbf{L}$ & labour force \\
\hline $\mathbf{M}$ & intermediate composite output \\
\hline $\mathbf{N}^{\mathrm{d}}, \mathbf{N}^{\mathrm{s}}, \mathbf{N}$ & labour demand, labour supply and labour employment \\
\hline $\mathbf{Q}$ & commodity/activity output \\
\hline $\mathbf{R}$ & intermediate demand \\
\hline $\mathbf{T}$ & nominal transfers from outwith the region \\
\hline $\mathbf{V}$ & value added \\
\hline $\mathbf{X}$ & exports \\
\hline $\mathbf{Y}$ & household nominal income \\
\hline $\mathbf{b}_{\mathrm{ij}}$ & elements of capital matrix \\
\hline cpi, kpi & consumer and capital price indices \\
\hline d & physical depreciation \\
\hline h & capital stock adjustment parameter \\
\hline pm & price intermediate composite \\
\hline pq & vector of commodity prices \\
\hline pv & price of value added \\
\hline $\mathbf{t}_{\mathrm{n}}, \mathbf{t}_{\mathrm{k}}$ & average direct tax on labour and capital income \\
\hline $\mathbf{u}$ & unemployment rate \\
\hline $\mathbf{w}_{\mathrm{n}}, \mathbf{w}_{\mathrm{k}}$ & price of labour to the firm, capital rental \\
\hline$\Psi$ & share of factor income retained in region \\
\hline$\theta$ & consumption weights \\
\hline$\gamma$ & capital weights \\
\hline
\end{tabular}


FIGURES (COLOUR)

Figure1. Production structure of each sector $i$ in the 25 sector/com modity UKENVI KLEM framework

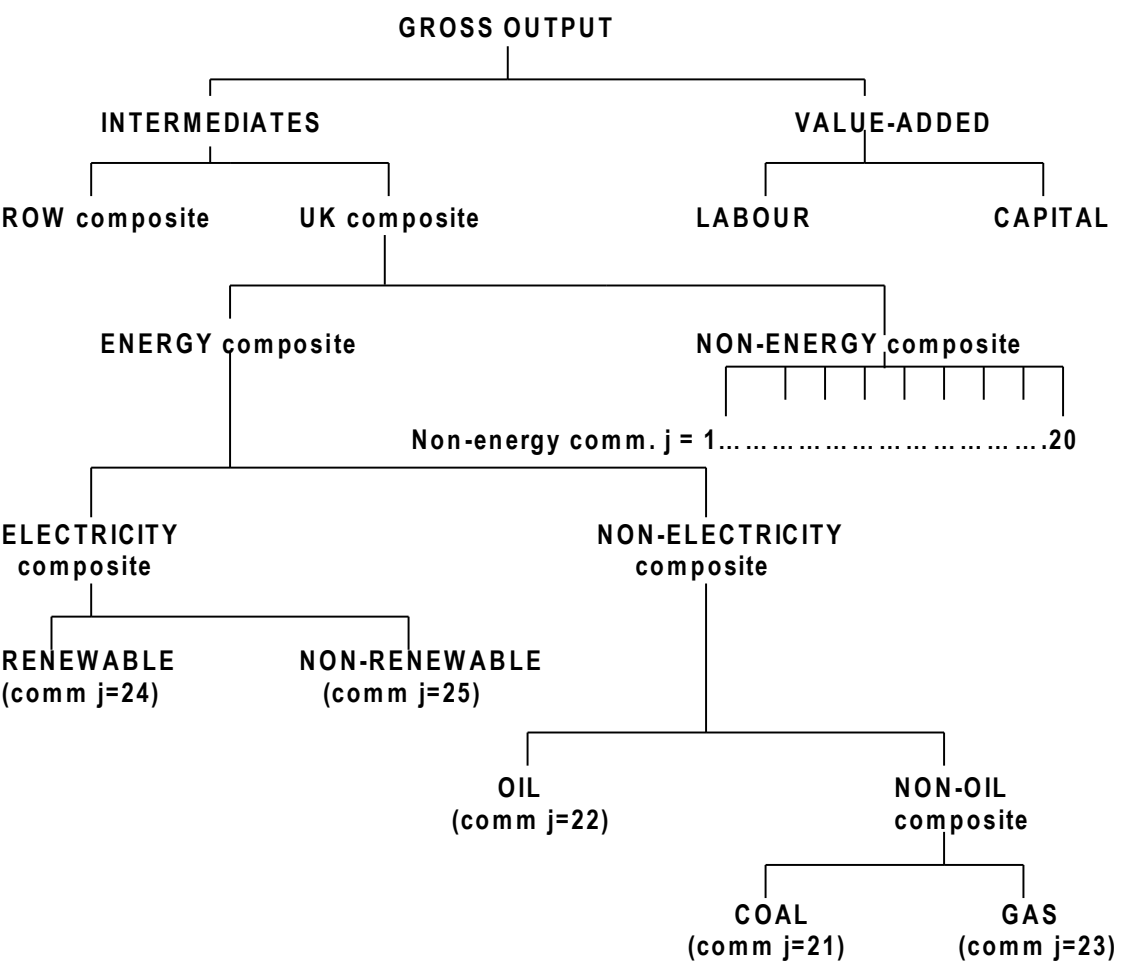




\section{TABLES}

Table 1. Sectoral breakdown of the 2000 UKENVI model

\begin{tabular}{|c|l|c|}
\hline \multicolumn{2}{|l|}{ IOC } \\
\hline 1 & Agriculture, forestry and fishing & $1,2,3$ \\
2 & Other mining and quarrying, including oil and gas extraction & $5,6,7$ \\
3 & Mfr - Food and drink & 8 to 20 \\
4 & Mfr - Textiles & 21 to 30 \\
5 & Mfr - Pulp, paper and articles of paper and board & 32 to 33 \\
6 & Mfr - Glass and glass products, ceramic goods and clay products & 49 to 51 \\
7 & Mfr - Cement, lime plaster and articles in concrete, plaster and cement a & 52 to 53 \\
8 & Mfr - Iron, steel first processing, and casting & 54 to 56 \\
9 & Mfr - Other metal products & 57 to 61 \\
10 & Mfr - Other machinery & 62 to 68 \\
11 & Mfr - Electrical and electronics & 69 to 76 \\
12 & Mfr - Other manufacturing & $31,34,36-48,77-84$ \\
13 & Water & 87 \\
14 & Construction & 88 \\
15 & Distribution and transport & 89 to 97 \\
16 & Communications, finance and business & 107,109 to 114 \\
17 & Research and development & 108 \\
18 & Public admin and education & $115+116$ \\
19 & Health and social work & $117+118$ \\
20 & Other services & $119-123$ \\
\hline & ENERGY & \\
21 & COAL (EXTRACTION) & 4 \\
22 & OIL (REFINING \& DISTR OIL AND NUCLEAR) & 35 \\
23 & GAS & 86 \\
& ELECTRICITY & 85 \\
24 & Renewable (hydro and wind) & \\
25 & Non-renewable (coal, nuke and gas) & \\
\hline
\end{tabular}


Table 2. The aggregate impact of a $5 \%$ increase in energy efficiency (locally supplied inputs) in all production sectors in the UK economy

(Percentage changes from base year equilibrum) - Base Case Scenario

\begin{tabular}{|l|c|c|}
\hline & Short-run & Long-run \\
\cline { 2 - 3 } GDP (income measure) & & \\
Consumption & 0.11 & 0.17 \\
Investment & 0.37 & 0.34 \\
Exports & 0.06 & 0.14 \\
Imports & -0.03 & 0.22 \\
Nominal before-tax wage & -0.23 & -0.21 \\
Real T-H consumption wage & 0.01 & 0.07 \\
Consumer price index & 0.28 & 0.30 \\
Total employment (000's): & -0.27 & -0.23 \\
Unemployment rate $(\%)$ & & \\
Total population (000's) & 0.20 & 0.21 \\
Total consumption UK electricity & -2.44 & -2.61 \\
Electricity rebound effect (\%) & 0.00 & 0.00 \\
& & -2.76 \\
Total consumption UK non-electricity energy & -1.45 & 23.1 \\
Non-electricity energy rebound effect (\%) & 59.6 & -2.05 \\
\hline
\end{tabular}

Table 3. Sensitivity analysis - simulation identifier

\begin{tabular}{|c|c|c|c|c|c|c|c|c|c|c|c|c|c|c|}
\hline & Trade & & & & & & & & & & & & & \\
\hline Production & $0(0.064)$ & 0.1 & 0.3 & 0.5 & 0.8 & $C D$ & 1.1 & 1.3 & 1.5 & 1.8 & 2 & 3 & 4 & 5 \\
\hline $0(0.064)$ & 1 & 2 & 3 & 4 & 5 & 6 & 7 & 8 & 9 & 10 & 11 & 12 & 13 & 14 \\
\hline 0.1 & 15 & 16 & 17 & 18 & 19 & 20 & 21 & 22 & 23 & 24 & 25 & 26 & 27 & 28 \\
\hline 0.3 & 29 & 30 & 31 & 32 & 33 & 34 & 35 & 36 & 37 & 38 & 39 & 40 & 41 & 42 \\
\hline 0.5 & 43 & 44 & 45 & 46 & 47 & 48 & 49 & 50 & 51 & 52 & 53 & 54 & 55 & 56 \\
\hline 0.8 & 57 & 58 & 59 & 60 & 61 & 62 & 63 & 64 & 65 & 66 & 67 & 68 & 69 & 70 \\
\hline CD (0.999999) & 71 & 72 & 73 & 74 & 75 & 76 & 77 & 78 & 79 & 80 & 81 & 82 & 83 & 84 \\
\hline 1.3 & 99 & 100 & 101 & 102 & 103 & 104 & 105 & 106 & 107 & 108 & 109 & 110 & 111 & 112 \\
\hline 1.5 & 113 & 114 & 115 & 116 & 117 & 118 & 119 & 120 & 121 & 122 & 123 & 124 & 125 & 126 \\
\hline 1.8 & 127 & 128 & 129 & 130 & 131 & 132 & 133 & 134 & 135 & 136 & 137 & 138 & 139 & 140 \\
\hline 2 & 141 & 142 & 143 & 144 & 145 & 146 & 147 & 148 & 149 & 150 & 151 & 152 & 153 & 154 \\
\hline
\end{tabular}


Table 4. Results of sensitivity analysis of non-electricity energy rebound effects in the UK economy in response to a $5 \%$ exogenous improvement in energy efficiency in production (applied to use of locally supplied energy)

SHORT RUN NON-ELECTRICITY REBOUND

\begin{tabular}{|c|c|c|c|c|c|c|c|c|c|c|c|c|}
\hline Production & 0.3 & 0.5 & 0.8 & $C D$ & 1.1 & 1.3 & 1.5 & 1.8 & 2 & 3 & 4 & 5 \\
\hline $0(0.064)$ & * & " & & 25.69 & 28.64 & 33.78 & 38.08 & 43.38 & 46.33 & 56.62 & 62.82 & 66.98 \\
\hline$\left.0.1\right|^{*}$ & * & & 15.96 & 22.53 & 25.43 & 30.58 & 35.02 & 40.64 & 43.85 & 55.59 & 63.07 & 68.30 \\
\hline 0.3 & 1.27 & 14.87 & 25.98 & 31.84 & 34.50 & 39.40 & 43.85 & 49.81 & 53.39 & 67.86 & 78.39 & 86.48 \\
\hline 0.5 & 17.53 & 34.66 & 46.15 & 51.96 & 54.59 & 59.48 & 63.95 & 70.05 & 73.78 & 89.33 & 101.28 & 110.78 \\
\hline 0.8 & 43.38 & 67.70 & 80.79 & 86.96 & 89.72 & 94.81 & 99.49 & 105.89 & 109.60 & 126.77 & 140.25 & 151.30 \\
\hline$C D(0.999999)$ & 69.68 & 91.02 & 102.94 & 108.84 & 111.53 & 116.54 & 121.18 & 127.64 & 131.65 & 149.16 & 163.41 & 175.26 \\
\hline 1.1 & 67.59 & 102.11 & 117.57 & 124.36 & 127.35 & 132.83 & 137.83 & 144.67 & 148.92 & 167.25 & 182.12 & 194.50 \\
\hline 1.3 & 81.76 & 125.35 & 142.77 & 150.07 & 153.26 & 159.06 & 164.33 & 171.54 & 175.99 & 195.33 & 211.13 & 224.39 \\
\hline$\left.1.5\right|^{*}$ & & 148.64 & 168.36 & 176.28 & 179.68 & 185.84 & 191.42 & 199.01 & 203.72 & 224.12 & 240.89 & 255.05 \\
\hline$\left.1.8\right|^{*}$ & & 183.46 & 207.36 & 216.32 & 220.12 & 226.91 & 233.00 & 241.26 & 246.36 & 268.52 & 286.82 & 302.37 \\
\hline $2 *$ & & 206.46 & 233.70 & 243.48 & 247.56 & 254.83 & 261.29 & 270.05 & 275.44 & 298.85 & 318.26 & 334.78 \\
\hline
\end{tabular}

LONG RUN NON-ELECTRICITY REBOUND

\begin{tabular}{|c|c|c|c|c|c|c|c|c|c|c|c|c|}
\hline Production & 0.3 & 0.5 & 0.8 & $C D$ & 1.1 & 1.3 & 1.5 & 1.8 & 2 & 3 & 4 & 5 \\
\hline $0(0.064)$ & * & & & .13 .73 & .12 .26 & -9.53 & -6.96 & -3.34 & -1.05 & 9.44 & 18.79 & 27.32 \\
\hline $0.1{ }^{*}$ & * & & . 12.34 & -9.14 & -7.67 & -4.89 & -2.28 & 1.38 & 3.70 & 14.31 & 23.78 & 32.38 \\
\hline 0.3 & 1.16 & 6.70 & 12.99 & 16.47 & 18.08 & 21.10 & 23.91 & 27.85 & 30.34 & 41.62 & 51.61 & 60.66 \\
\hline 0.5 & 26.00 & 31.89 & 38.67 & 42.44 & 44.19 & 47.44 & 50.47 & 54.70 & 57.35 & 69.35 & 79.90 & 89.43 \\
\hline 0.8 & 64.01 & 70.38 & 77.89 & 82.09 & 84.02 & 87.67 & 91.03 & 95.72 & 98.52 & 111.80 & 123.25 & 133.53 \\
\hline CD (0.999999) & 91.29 & 96.15 & 102.26 & 105.86 & 107.57 & 110.81 & 113.89 & 118.26 & 121.05 & 133.83 & 145.24 & 155.63 \\
\hline 1.1 & 102.91 & 109.76 & 117.97 & 122.61 & 124.76 & 128.76 & 132.49 & 137.66 & 140.89 & 155.27 & 167.71 & 178.82 \\
\hline 1.3 & 129.37 & 136.52 & 145.21 & 150.14 & 152.42 & 156.70 & 160.66 & 166.17 & 169.61 & 184.86 & 198.00 & 209.71 \\
\hline $1.5{ }^{*}$ & & 163.70 & 172.87 & 178.08 & 180.50 & 185.05 & 189.27 & 195.12 & 198.76 & 214.95 & 228.83 & 241.16 \\
\hline $1.8 *$ & & 205.30 & 215.16 & 220.83 & 223.46 & 228.42 & 233.02 & 239.41 & 243.40 & 261.03 & 276.10 & 289.45 \\
\hline $2 *$ & & 233.60 & 243.92 & 249.89 & 252.68 & 257.91 & 262.78 & 269.55 & 273.77 & 292.41 & 308.32 & 322.40 \\
\hline
\end{tabular}

Table 5. Results of sensitivity analysis of GDP effects in the UK economy in response to a $5 \%$ exogenous improvement in energy efficiency in production (applied to use of locally supplied energy)

SHORT RUN GDP:

\begin{tabular}{|c|c|c|c|c|c|c|c|c|c|c|c|c|}
\hline Production & 0.3 & 0.5 & 0.8 & $C D$ & 1.1 & 1.3 & 1.5 & 1.8 & 2 & 3 & 4 & 5 \\
\hline \multirow{11}{*}{. } & * & * & & 0.05 & 0.05 & 0.06 & 0.06 & 0.06 & 0.06 & 0.06 & 0.06 & 0.05 \\
\hline & * & & 0.07 & 0.07 & 0.07 & 0.07 & 0.07 & 0.07 & 0.07 & 0.07 & 0.07 & 0.07 \\
\hline & 0.00 & 0.07 & 0.10 & 0.10 & 0.10 & 0.10 & 0.11 & 0.11 & 0.11 & 0.11 & 0.11 & 0.11 \\
\hline & -0.06 & 0.06 & 0.09 & 0.10 & 0.11 & 0.11 & 0.11 & 0.11 & 0.12 & 0.12 & 0.12 & 0.12 \\
\hline & -0.14 & 0.04 & 0.09 & 0.10 & 0.10 & 0.11 & 0.11 & 0.12 & 0.11 & 0.13 & 0.13 & 0.13 \\
\hline & -0.20 & 0.02 & 0.08 & 0.09 & 0.10 & 0.11 & 0.11 & 0.12 & 0.12 & 0.13 & 0.14 & 0.13 \\
\hline & -0.22 & 0.02 & 0.08 & 0.09 & 0.10 & 0.11 & 0.11 & 0.12 & 0.12 & 0.13 & 0.13 & 0.13 \\
\hline & -0.28 & 0.00 & 0.07 & 0.09 & 0.10 & 0.10 & 0.11 & 0.12 & 0.12 & 0.13 & 0.13 & 0.14 \\
\hline & & -0.01 & 0.07 & 0.09 & 0.09 & 0.10 & 0.11 & 0.12 & 0.12 & 0.13 & 0.13 & 0.14 \\
\hline & & -0.03 & 0.06 & 0.08 & 0.09 & 0.10 & 0.11 & 0.11 & 0.12 & 0.13 & 0.14 & 0.14 \\
\hline & & -0.04 & 0.06 & 0.08 & 0.09 & 0.10 & 0.11 & 0.11 & 0.12 & 0.13 & 0.14 & 0.14 \\
\hline
\end{tabular}

\begin{tabular}{|c|c|c|c|c|c|c|c|c|c|c|c|c|}
\hline Production & 0.3 & 0.5 & 0.8 & $C D$ & 1.1 & 1.3 & 1.5 & 1.8 & 2 & 3 & 4 & 5 \\
\hline Leontief & * & * & & 0.10 & 0.11 & 0.12 & 0.14 & 0.15 & 0.16 & 0.20 & 0.22 & 0.23 \\
\hline$\left.0.1\right|^{*}$ & * & & 0.07 & 0.10 & 0.11 & 0.12 & 0.14 & 0.16 & 0.16 & 0.20 & 0.22 & 0.23 \\
\hline 0.3 & -0.09 & -0.01 & 0.06 & 0.09 & 0.10 & 0.12 & 0.14 & 0.16 & 0.17 & 0.21 & 0.23 & 0.25 \\
\hline 0.5 & -0.11 & -0.03 & 0.05 & 0.08 & 0.09 & 0.12 & 0.13 & 0.16 & 0.17 & 0.21 & 0.24 & 0.26 \\
\hline 0.8 & -0.14 & -0.06 & 0.02 & 0.06 & 0.08 & 0.11 & 0.13 & 0.15 & 0.17 & 0.22 & 0.25 & 0.28 \\
\hline $\mathrm{CD}$ & -0.16 & -0.08 & 0.01 & 0.05 & 0.07 & 0.10 & 0.12 & 0.15 & 0.17 & 0.23 & 0.26 & 0.29 \\
\hline 1.1 & -0.17 & -0.09 & 0.00 & 0.04 & 0.06 & 0.09 & 0.12 & 0.15 & 0.17 & 0.23 & 0.27 & 0.29 \\
\hline 1.3 & -0.19 & -0.10 & -0.01 & 0.03 & 0.05 & 0.08 & 0.11 & 0.14 & 0.16 & 0.23 & 0.27 & 0.30 \\
\hline$\left.1.5\right|^{*}$ & & -0.13 & -0.03 & 0.02 & 0.04 & 0.07 & 0.10 & 0.14 & 0.16 & 0.23 & 0.28 & 0.31 \\
\hline$\left.1.8\right|^{*}$ & & -0.16 & -0.06 & -0.01 & 0.02 & 0.05 & 0.09 & 0.13 & 0.15 & 0.23 & 0.29 & 0.32 \\
\hline 2 & & -0.18 & -0.08 & -0.02 & 0.00 & 0.04 & 0.08 & 0.12 & 0.14 & 0.23 & 0.29 & 0.33 \\
\hline
\end{tabular}


Table 6 Impact on UK rebound effects of removing energy use in final consumption from rebound calculations

\begin{tabular}{|c|c|c|c|c|c|c|c|c|c|c|c|}
\hline & Trad & & & & & & & & & & \\
\hline Production & & 3 & 0.5 & 0.8 & $C D$ & 1.1 & 1.3 & 1.5 & 1.8 & 2 & 3 \\
\hline $0(0.064)$ & t & * & * & & 20.02 & 22.89 & 27.91 & 32.12 & 37.30 & 40.17 & 50.21 \\
\hline & & * & & 10.40 & 16.80 & 19.63 & 24.66 & 29.00 & 34.51 & 37.66 & 49.14 \\
\hline
\end{tabular}

\begin{tabular}{|c|c|c|c|c|c|c|c|c|c|c|c|}
\hline & Trad & & & & & & & & & & \\
\hline Production & & 3 & 0.5 & 0.8 & $C D$ & 1.1 & 1.3 & 1.5 & 1.8 & 2 & 3 \\
\hline $0(0.064)$ & * & * & * & & -17.99 & -16.73 & -14.31 & -12.01 & -8.71 & -6.59 & 3.26 \\
\hline 0. & & * & & -16.11 & -13.40 & -12.12 & -9.67 & -7.33 & -3.99 & -1.85 & 8.10 \\
\hline
\end{tabular}

Table 7. The aggregate impact of a $5 \%$ increase in energy efficiency (locally supplied inputs) in production sectors 1-20 (non-energy supply) in the UK economy

(Percentage changes from base year equilibrum) - Base Case Scenario

\begin{tabular}{|l|c|c|}
\hline & Short-run & Long-run \\
\hline GDP (income measure) & 0.04 & 0.08 \\
Consumption & 0.14 & 0.14 \\
Investment & 0.06 & 0.08 \\
Exports & 0.07 & 0.17 \\
Imports & $-\mathbf{0 . 0 7}$ & $-\mathbf{0 . 0 8}$ \\
Nominal before-tax wage & 0.06 & 0.08 \\
Real T-H consumption wage & 0.11 & 0.14 \\
Consumer price index & $-\mathbf{0 . 0 5}$ & $-\mathbf{0 . 0 6}$ \\
Total employment $(000$ 's): & 0.08 & 0.10 \\
Unemployment rate $(\%)$ & $-\mathbf{0 . 9 4}$ & -1.21 \\
Total population $(000$ 's) & $\mathbf{0 . 0 0}$ & 0.00 \\
Total consumption UK electricity & -1.09 & -1.47 \\
Electricity rebound effect $(\%)$ & 24.75 & -1.68 \\
Total consumption UK non-electricity energy & & -1.27 \\
Non-electricity energy rebound effect $(\%)$ & -1.07 & 17.34 \\
\hline
\end{tabular}


Table 8. The aggregate impact of a $5 \%$ increase in energy efficiency (locally supplied inputs) in production sectors 1-20 (non-energy supply) in the UK economy

(Percentage changes from base year equilibrum) - trade elasticities 1, production elasticities 0.064

\begin{tabular}{|l|c|c|}
\hline & Short-run & Long-run \\
\hline GDP (income measure) & 0.03 & 0.04 \\
Consumption & 0.18 & 0.10 \\
Investment & 0.01 & 0.00 \\
Exports & -0.05 & 0.14 \\
Imports & $-\mathbf{0 . 0 8}$ & -0.10 \\
Nominal before-tax wage & -0.04 & 0.00 \\
Real T-H consumption wage & 0.09 & 0.10 \\
Consumer price index & -0.12 & -0.11 \\
Total employment $(000$ 's): & 0.06 & 0.07 \\
Unemployment rate $(\%)$ & -0.78 & -0.91 \\
Total population $(000$ 's) & 0.00 & 0.00 \\
Total consumption UK electricity & -1.12 & -2.11 \\
Electricity rebound effect $(\%)$ & 22.43 & -45.81 \\
Total consumption UK non-electricity energy & & -1.82 \\
Non-electricity energy rebound effect $(\%)$ & -1.25 & -18.77 \\
\hline
\end{tabular}

